\title{
Molecular Characterization of Mutant Mouse Strains Generated from the EUCOMM/KOMP-CSD ES Cell Resource
}

\author{
Edward Ryder · Diane Gleeson - Debarati Sethi - Sapna Vyas · Evelina Miklejewska • \\ Priya Dalvi · Bishoy Habib · Ross Cook $\cdot$ Matthew Hardy $\cdot$ Kalpesh Jhaveri \\ Joanna Bottomley • Hannah Wardle-Jones · James N. Bussell • Richard Houghton • \\ Jennifer Salisbury • William C. Skarnes • Sanger Mouse Genetics Project • \\ Ramiro Ramirez-Solis
}

Received: 3 April 2013/ Accepted: 27 June 2013/Published online: 4 August 2013

(C) The Author(s) 2013. This article is published with open access at Springerlink.com

\begin{abstract}
The Sanger Mouse Genetics Project generates knockout mice strains using the EUCOMM/KOMP-CSD embryonic stem (ES) cell collection and characterizes the consequences of the mutations using a high-throughput primary phenotyping screen. Upon achieving germline transmission, new strains are subject to a panel of quality control (QC) PCR- and qPCR-based assays to confirm the correct targeting, cassette structure, and the presence of the $3^{\prime}$ LoxP site (required for the potential conditionality of the allele). We report that over $86 \%$ of the 731 strains studied showed the correct targeting and cassette structure, of which $97 \%$ retained the $3^{\prime}$ LoxP site. We discuss the characteristics of the lines that failed QC and postulate that the majority of these may be due to mixed ES cell populations which were not detectable with the original screening techniques employed when creating the ES cell resource.
\end{abstract}

Electronic supplementary material The online version of this article (doi:10.1007/s00335-013-9467-x) contains supplementary material, which is available to authorized users.

E. Ryder $(\bowtie) \cdot$ D. Gleeson - D. Sethi · S. Vyas .

E. Miklejewska $\cdot$ P. Dalvi - B. Habib - R. Cook · M. Hardy ·

K. Jhaveri · J. Bottomley · H. Wardle-Jones ·

J. N. Bussell · R. Houghton · J. Salisbury ·

W. C. Skarnes - Sanger Mouse Genetics Project

R. Ramirez-Solis $(\square)$

The Wellcome Trust Sanger Institute, Hinxton, Cambridgeshire CB10 1SA, UK

e-mail: er1@sanger.ac.uk

R. Ramirez-Solis

e-mail: rrs@sanger.ac.uk

\section{Introduction}

The extensive genetic resources available for the mouse, including the sequencing and annotation of the genomes of multiple inbred laboratory strains (Church et al. 2009; Keane et al. 2011; Flicek et al. 2012; Wong et al. 2012), have facilitated comprehensive comparisons with the human genome (Guigo et al. 2003; Zheng-Bradley et al. 2010; Mouse ENCODE Consortium et al. 2012). This makes the mouse a powerful tool for both investigating gene function and modelling disease progression in mammalian systems. This importance can be demonstrated by the wealth of resources available for researchers studying human diseases and genetic disorders, including (but not limited to) cancer (Frese and Tuveson 2007; Kim and Baek 2010; Leystra et al. 2012), visual (Gao et al. 2002; van de Pavert et al. 2007) and auditory dysfunctions (Leibovici et al. 2008; Spiden et al. 2008), neurodegenerative conditions (Games et al. 1995; Schilling 1999; Ravikumar et al. 2004; Wirths and Bayer 2010), and diabetes (Cho et al. 2001; Duan et al. 2004). There are over 1,100 human diseases with one or more mouse models, and over 3,600 mouse genotypes model human disease as reported at the Mouse Genome Database (MGD) (http://www.informatics. jax.org, December 2012). To facilitate these investigations, several large-scale efforts to create knockout mutations in mice have been established (Bradley et al. 2012) by the systematic construction of targeted mutations (Valenzuela et al. 2003; Prosser et al. 2011; Skarnes et al. 2011). Currently, the largest resource of targeted mutations is the EUCOMM/KOMP-CSD mouse embryonic stem cell (ESC) collection (Skarnes et al. 2011), which is based on JM8 agouti or non-agouti C57BL/6N ES cells (Pettitt et al. 2009). The structure and modification of the promoterdriven "knockout-first" EUCOMM/KOMP-CSD allele, 
which forms the majority of the collection, is shown in Fig. 1.

The EUCOMM/KOMP-CSD collection, along with those generated by Regeneron, and the Canadian NorComm programme form the International Mouse Knockout Consortium (IKMC) resource (Collins et al. 2007; Ringwald et al. 2011; Bradley et al. 2012) and are the main source of ES cells used for mouse production by the International Mouse Phenotyping Consortium (IMPC) (Brown and Moore 2012).

The goal of the IMPC is to generate knockout strains for all protein-coding genes in the mouse on a pure C57BL/6N genetic background, and to elucidate gene function by use of a broad-spectrum high-throughput primary phenotyping screen. These phenotypes can then be studied in more depth by the scientific community at large within specialized areas of interest.

The aims of the IMPC overlap with the Wellcome Trust Sanger Mouse Genetics Project (Sanger MGP) (White et al. 2013) which was formed in 2006 to generate and phenotype 200 mutant mouse strains per year using a battery of tests designed to detect changes in a variety of systems, including metabolism, dysmorphology, behaviour, cardiovascular, immunity, visual and auditory response, viability, and homozygous lethality (Ayadi et al. 2012). Strains are available to the scientific community directly from Sanger Institute while colonies are actively breeding, and from the European Mutant Mouse Archive (Wilkinson et al. 2010) or KOMP Repository (Lloyd 2011) once archived. The primary phenotypic data are also readily available at the Sanger Mouse Portal (http://www.sanger.ac.uk/mouseportal).

At the time of writing, the EUCOMM/KOMP-CSD ES clone collection consisted of targeted clones for 12,350 genes, $56 \%$ of the 22,147 CCDS (Pruitt et al. 2009) gene models present in Ensembl (Flicek et al. 2012). The resource was generated by use of a high-throughput modular gateway-based vector construction and positive-negative selection for high-efficiency targeting in ES cells (Skarnes et al. 2011). Clones were then screened by longrange PCR and sequencing to confirm targeting and the presence of the $3^{\prime} \operatorname{lox} P$ site that is required for the conditionality of the mutant allele. Although this approach is appropriate for a high-throughput pipeline in terms of cost and speed, it does have its limitations. For example, longrange PCR is likely to miss mutations within the cassette and is not able to detect mixed ESC populations. As the resource is exploited to generate mouse lines, it will be important to ascertain the molecular structure of the alleles transmitted to mice.

Here we present a detailed and extensive molecular characterization of the mutant alleles in mouse strains generated from the resource. We demonstrate that although the majority of the mouse lines produced by Sanger MGP from the EUCOMM/KOMP-CSD collection are correct, some problematic events were detected. We have developed a set of quality control (QC) criteria and assays to screen out affected strains as early as possible following germline transmission of the incorrect alleles.

\section{Materials and Methods}

The care and use of all mice in this study were in accordance with the UK Home Office regulations, UK Animals (Scientific Procedures) Act of 1986, and were approved by

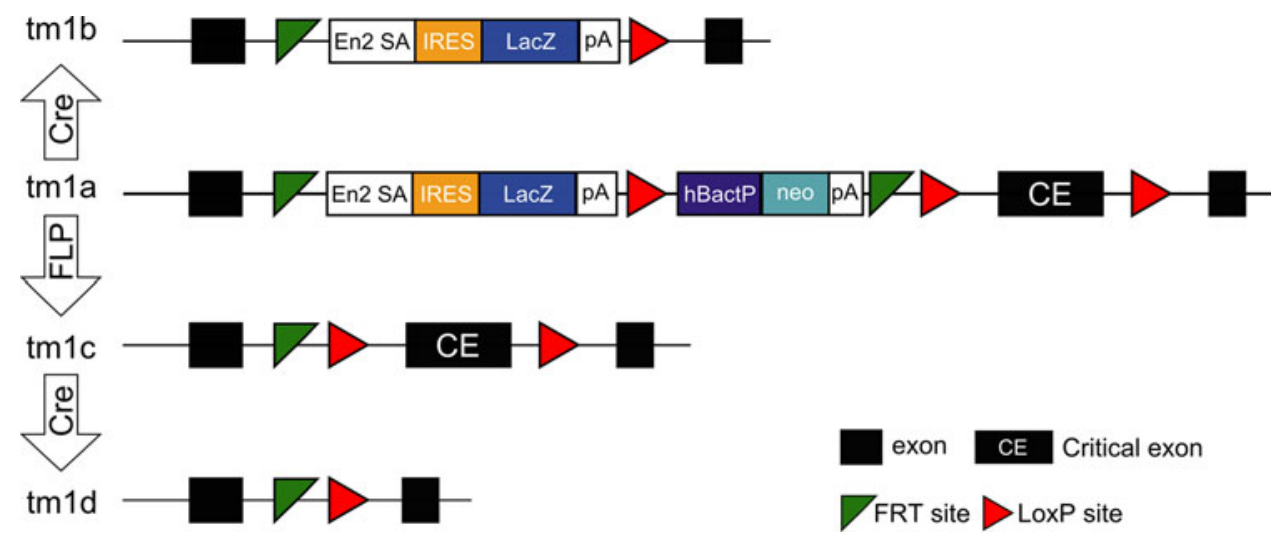

Fig. 1 EUCOMM/KOMP-CSD allele structure and conversion. The EUCOMM/KOMP-CSD allele "knockout-first" allele (tm1a) contains an IRES:lacZ trapping cassette and a floxed promoter-driven neo cassette inserted into the intron of the targeted gene. The presence of an Engrailed (En2) splice acceptor disrupts gene function, resulting in a lacZ fusion for studying gene expression localisation. Exposure to a source of Flp recombinase removes the gene trap cassette, converts the "knockout-first" allele to a conditional allele (tm1c) and restores the gene's activity. Subsequent exposure to Cre recombinase will then delete the floxed exon of the tm1c allele resulting in a frameshift and null mutation (tm1d). Cre recombinase can also be used to convert the tm1a allele to the tm1b form and generate a nonconditional lacZtagged null allele without the promoter-driven neo cassette 
the Wellcome Trust Sanger Institute Ethical Review Committee.

\section{A Minimum Standard for Mouse QC}

The high-throughput nature of the Sanger MGP makes it impractical to apply a QC strategy based on Southern blot analysis. Thus, our QC strategy is centred on a set of PCR-based methods configured to detect abnormalities in the identity of the targeted gene, the presence/absence of the $3^{\prime}$ loxP site, and the number of vector insertions. Our strategy complies with the IKMC guidelines to include at least one test in each of the four different categories (Table 1).

High-Throughput Genotyping and QC Tests used by the Sanger Institute MGP

For rapid and universal detection of potential germline transmission of the mutant allele from the initial breeding of chimeras (crossed to $\mathrm{C} 57 \mathrm{BL} / 6 \mathrm{~N}$ Taconic), $\mathrm{G}_{1}$ carriers are identified by a universal qPCR assay designed to the neomycin selection marker in the targeting cassette. Gene identification and QC of the allele are then performed on all $\mathrm{G}_{1}$ heterozygotes before switching to the neo qPCR for routine genotyping and phenotyping cohort production. Gene-specific assays and further QC are then performed on selected homozygous mutant animals before and after phenotyping. The QC methods performed on mice are outlined in Fig. 2. They are a mixture of end-point short range PCR (srPCR) and copy number counting qPCRbased assays designed to both the mutant and wild-type (WT) alleles. The presence or absence of the $3^{\prime} \operatorname{lox} P$ site in conditional ready "knockout-first" lines was determined by either a universal PCR assay (primers designed to the cassette and linker sequences $3^{\prime}$ to the $\operatorname{lox} P$ insertion site) or, where no product was detected, a PCR using two genespecific PCRs followed by sequencing.

Further details of the tests used at the Sanger Institute, including primer sequences and reaction conditions, can be found in Supplementary Information S1 and also in the IKMC knowledge base (http://www.knockoutmouse.org/ $\mathrm{kb} / 2)$.

\section{Results}

During the period between September 2006 and November 2011, a total of 731 EUCOMM/KOMP ESC clones were microinjected (582 MGP, 94 EUMODIC, and 48 KOMP2funded) and subsequently achieved germline transmission, of which 632 mouse colonies (86\%) passed QC.

Details of the assays that have been performed on the released lines are shown in Fig. 3; not all assays were completed on all lines released to the community as the QC methods evolved as the MGP has progressed and gained experience with the KOMP and EUCOMM ES cell resource.

\section{Analysis of Lines that Failed QC}

\section{Correct Gene Targeting (Gene id and Mutation Structure)}

A total of 99 lines did not pass our QC protocol, $14 \%$ of the total transmitting clones, the reasons for which are summarized in Table 2. Failures in the experimental protocols can be categorized into two main classes: technical problems and real gene-targeting errors. As a general workflow, when a QC failure was obtained it was assumed to be a technical problem and further effort was made to verify the correct gene targeting. A small subset of lines that failed targeting by PCR methods were analysed by

Table 1 IKMC minimum allele QC standards

\begin{tabular}{|c|c|c|}
\hline QC category & QC test (at least one per category) & Stage \\
\hline \multirow[t]{5}{*}{ Confirm targeting of the allele } & Southern blot with neo or external probe & $\mathrm{ESC}$ or mice \\
\hline & Loss of wild-type allele (LoA) qPCR & Mice \\
\hline & $5^{\prime}$ and $3^{\prime} \mathrm{LRPCR}$ & Mice \\
\hline & Absence of a WT-specific short-range PCR (srPCR) product in homozygous mice & Mice \\
\hline & Gene expression analysis on mRNA or protein & Mice \\
\hline Confirm structure of the cassette & $\begin{array}{l}\text { srPCR on various parts of the cassette (e.g., mutant-specific srPCR, } \\
\text { lacZ, neo, cassette ends, neo, or lacZ count by qPCR }\end{array}$ & Mice \\
\hline $\begin{array}{l}\text { Confirm conditionality of the } \\
\text { tm la allele }\end{array}$ & Gene-specific or universal srPCR to detect the $\operatorname{lox} P$ site $3^{\prime}$ to the $\mathrm{CE}$ & Mice \\
\hline \multirow{2}{*}{$\begin{array}{l}\text { Confirm absence of additional } \\
\text { insertions }\end{array}$} & Southern blot with neo probe & $\mathrm{ESC}$ or mice \\
\hline & neo or lacZ count by $\mathrm{qPCR}+$ vector backbone PCR & Mice \\
\hline
\end{tabular}


WT allele

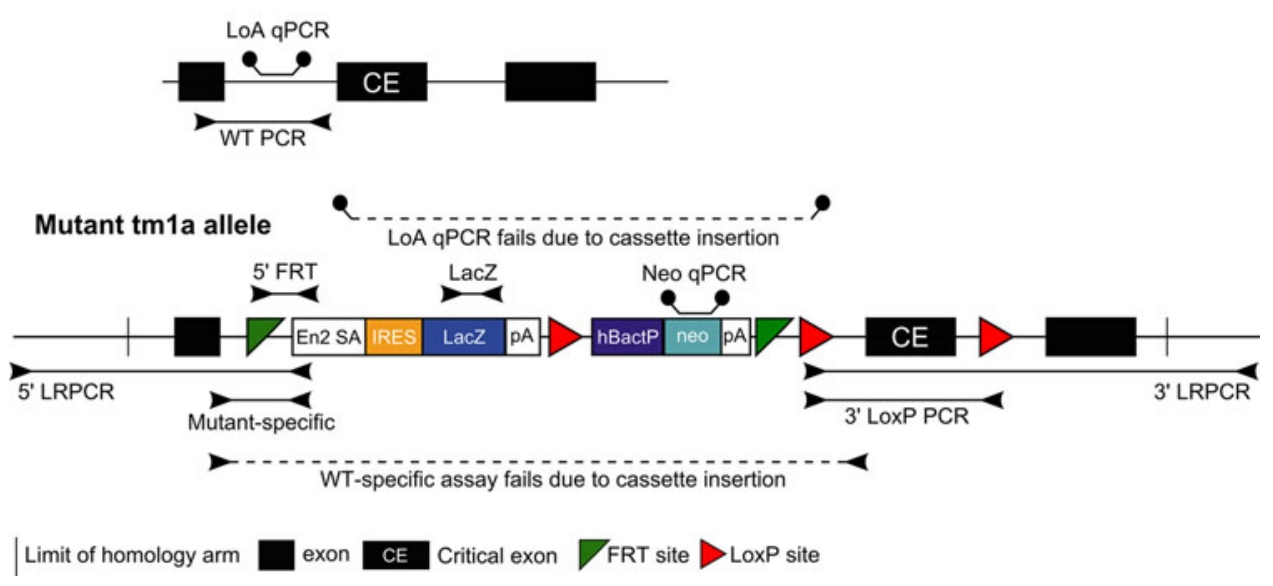

Fig. 2 QC tests performed on mouse tissue samples (promoter-driven design shown for illustrative purposes). WT PCR: A gene-specific assay that detects only the wild-type allele. Insertion of the cassette makes the product too large to be amplified with the conditions used. Mutant PCR: A gene-specific assay that uses one gene-specific primer and one universal cassette primer and amplifies only the mutant allele. This can be used in conjunction with the WT PCR to genotype mice using gel-based methods. 5'FRT: Universal PCR assay to determine presence of the $5^{\prime}$ end of the cassette and $5^{\prime}$ FRT site. neo qPCR: Universal real-time PCR assay to determine the presence and copy number of the neomycin selection cassette. LacZ: a universal PCR assay to determine presence/absence of the lacZ gene. LoA qPCR: Loss of WT allele qPCR assay that determines the copy number of the WT (nontargeted) allele. Targeted clones will see a reduction in copy number. LoxP: a universal assay to determine presence of the loxP site $3^{\prime}$ to the critical exon. Gene-specific primers can also be used if the critical exon region is very large. LRPCR: Long-range PCR pairs one primer within the cassette with a gene-specific primer outside of the homology arm and is used to confirm the targeting of the allele. Two PCR-based tests are also used to detect the presence of vector backbone incorporation into the genome, which would suggest an improper targeting event

Fig. 3 Quality control status for mouse strains made available to the community. Each stroke represents one test performed per mouse colony. The majority of targeting confirmation is provided by loss of WT allele qPCR and/or loss of a wild-type amplicon using gel-based short-range PCR. Strains that have lost the $3^{\prime}$ lox $P$ and therefore the conditionality capability are still made available to the research community as they may be of use as a loss-of-function mutant

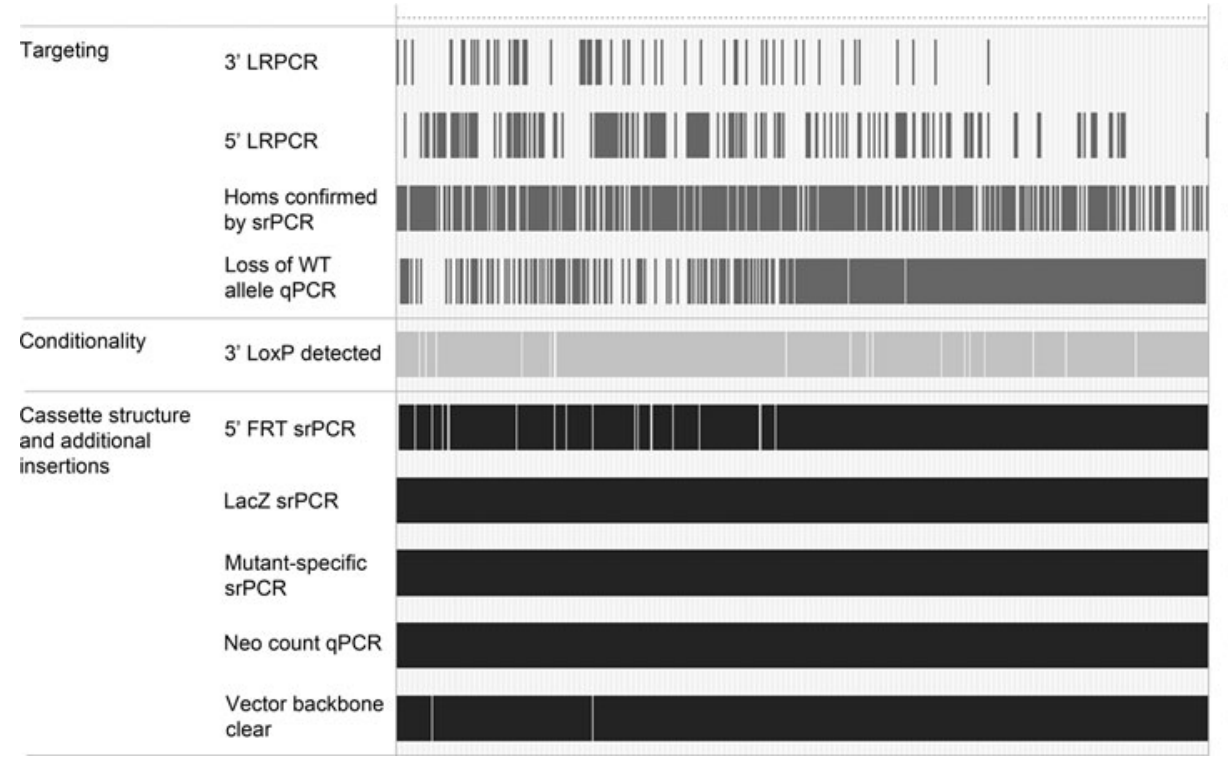

Southern blot and also showed incorrect targeting (data not shown). Lines that initially failed were investigated with additional tests to confirm the results, usually by analysis of a qPCR assay designed to the critical exon (CE) region (if more than two copies are detected in heterozygotes or homozygotes compared to wild types, it confirms that the targeting is incorrect) or by redesign of PCR primers. A subset of lines subsequently passed QC on further testing and are not included in Table 2; Zfp106 EPD0033_4_C03, for example, failed to confirm homozygotes detected by qPCR with a srPCR assay, but correct targeting was suggested by LRPCR and gene expression analysis. The mutant allele design for Zfp 106 is in an area of high-density repeats which resulted in the initial srPCR assays amplifying nonspecific products; subsequent assay redesign produced the desired result which was later confirmed by loss of WT allele qPCR. The colony for Kng2 EPD0554_8_A01 failed loss-of-WT-allele qPCR at the $\mathrm{G}_{1}$ 
stage but passed both $5^{\prime}$ and $3^{\prime}$ LRPCR. Analysis of the cassette insertion region of the mutant allele revealed that $408 \mathrm{bp}$ of the flanking sequence was duplicated in Kngl and prevented the qPCR assay from accurately detecting the loss of copy number. The WT and mutant PCR assays were redesigned to avoid the duplicated region and the targeting confirmed by failure to amplify a WT band in homozygotes detected by neo count qPCR.

Most cases of QC failures involving the cassette structure were due to a deletion of the $5^{\prime}$ end. To investigate whether the size of the deletion was variable or from a fixed point, a tiling PCR assay covering the length of the L1L2_Bact_P cassette (the most frequently used in the EUCOMM/KOMP-CSD resource) was designed and tested. We found that the amount of genetic material deleted was not constant between the QC-failed lines tested; for example, the 2210012G02Rik EPD0131_3_F05 line showed a deletion of the splice acceptor and most of the IRES element (Supplementary Information S2), whereas Myo10 EPD0272_4_C10 had a deletion of the entire cassette up to the neo selection marker. Some issues were also observed internal to the cassette; Btbd11 EPD0463_1_A11 was shown to carry a deletion of 929 bp located 940 bp $3^{\prime}$ of the lac $Z$ gene initiation site. The original "final vector" DNA and four alternative ESC clones were checked and did not carry this deletion, suggesting that it occurred during electroporation and subsequent homologous recombination (Supplementary Information S3).

We found that the cell line used also had a significant effect on the subsequent QC status. Colonies from the JM8.F6 cell line showed $50 \%$ fewer QC failures (12/159, $P=0.0216$ ), whereas those from the JM8A1.N3 cell line produced over twice as many failures than the average failure rate $(13 / 43,30 \%, P=0.0182)$. This suggests that the JM8A1.N3 cells may have a greater proportion of mixed populations of targeted and nontargeted clones compared to the other lines, and the nontargeted cells then go on to constitute the germ cells of the chimeras. The JM8A3.N1 and JM8.N4 cell lines did not show a significant difference $(P=0.202$ and $P=0.582$, respectively).

Table 2 QC failures mouse colonies

\begin{tabular}{lll}
\hline Reason for QC failure & $\begin{array}{l}\text { No. of } \\
\text { lines }\end{array}$ & $\begin{array}{l}\% \text { total } \\
\text { lines }\end{array}$ \\
\hline $\begin{array}{l}\text { Incorrect targeting } \\
\text { 5' end of cassette missing } \\
\quad \text { and incorrect targeting }\end{array}$ & 58 & 7.9 \\
$\quad \begin{array}{l}\text { Incorrect neo count } \\
\text { Incorrect neo count and incorrect targeting }\end{array}$ & 4 & 3.3 \\
5' end of cassette missing $^{\prime}$ Total & 2 & 1.5 \\
\hline
\end{tabular}

No significant difference $(P=0.123)$ was detected with the type of mutation used for the allele from conditionalready designs (91/608 lines) compared to deletion-based designs ( $8 / 27$ lines).

\section{Loss of the $3^{\prime}$ loxP Site}

The $3^{\prime}$ loxP site can be lost from the mutant allele during homologous recombination as it is embedded within the $3^{\prime}$ homology arm and at a distance from the selection cassette. From a total of 600 of "knockout-first conditional ready" tm1a lines tested, we found $18(3 \%)$ that did not carry the $3^{\prime}$ loxP site that was detected during the original ES cell production screen, possibly due to mixed ESC colonies. As expected, this event is ESC clone-specific, and, thus, differences in presence/absence of the $3^{\prime}$ lox $P$ site in different clones from the same electroporation for the same gene were observed in some cases where duplicate microinjections were performed. For example, the genes Mlec, Smyd5, and Pabpc4: mice derived from clones EPD0 600_1_A06, EPD0027_5_G01, and EPD0025_3_C07 did not possess a $3^{\prime}$ loxP site, whereas those derived from EPD0600_1_H03, EPD0027_5_A02, and EPD0025_ 3_C08 did. These results highlight the need to reconfirm the presence of the $3^{\prime}$ lox $P$ site in the mice generated from the ESC resource if conditional mutants are needed in a downstream research. Lines that do not possess the $3^{\prime}$ lox $P$ site are still useful and are made available to the scientific community by Sanger MGP, but as tm1e "targeted nonconditional" mutants.

\section{Evidence for Mixed ESC Populations}

The discordance between the targeting screens performed at ESC clone production and the subsequent failure rate in mouse colonies may be due to (1) a mixture of targeted and nontargeted clones in the ESC population (where the nontargeted cell contamination preferentially contributes to the germline in the chimera), (2) a higher than expected false-positive PCR rate in the ESC screening during production, or (3) incomplete assessment of the ES cells resulting in structural and targeting issues being missed even if the cell population was pure.

An additional long-range PCR QC step on the ES cells based on either the $5^{\prime}$ or the $3^{\prime}$ homology arm of the mutant allele prior to microinjection did not reduce the subsequent failure rate in mouse colonies. This was unexpected and suggests that mixed-cell populations are a major factor; the end-point-based LRPCR reaction detects the targeted cells but does not give information that nontargeted cells are also present.

Further evidence for mixed populations of ESC colonies was detected in a small number of mouse colonies, where 
transmission of two different alleles was detected by analysis of the $\mathrm{G}_{1}$ (chimera $\times$ C57BL/6N Taconic) animals. In most cases, these originated from the different chimeras [examples include Tmem126a EPD0409_3_A09 (Supplementary Information S4), Slc25a21 EPD008 5_1_D04, G3bp2 EPD0598_4_D01, Ide EPD0158_4_G09, and Mtap2 EPD0416_2_A02]. These incorrect alleles were not selected for further expansion. Multiple-targeting events were also observed originating from the same chimera [e.g., Srrm4 EPD0538_3_A07 (Supplementary Information S4), Bail EPD0675_3_C01, and Rftn2 EPD0176_4_A01], where some offspring showed correct targeting and cassette structure and other heterozygous littermates did not.

Evidence for incorrect targeting events of the mutant allele is exemplified by Tcf7l2 EPD0130_2_C06 and Crtc2 EPD0197_3_C08; both passed the 5' and 3' LRPCR QC assays in the mouse line but failed to detect a loss in copy number of the WT allele by qPCR. An additional copy of the floxed $\mathrm{CE}$ region was also detected, suggesting that the mutant allele had targeted the correct locus but not completely replaced the endogenous form.

These results underline the need to carefully check each $\mathrm{G}_{1}$ individual used for expanding the colony, as transmission of the incorrect allele may seriously affect the utility of the mouse line or give misleading phenotyping results. With a few additional QC steps, however, any issues discovered at this early stage can easily be filtered out and the correctly targeted mice then used to expand the colony. Although these mixed events were a small percentage ( $\sim 2 \%$ ) of the overall numbers of lines produced, they can result in a disproportionate amount of effort and costs needed to correct them once the colony has expanded, if they are detected at all.

However, one incorrect clone does not mean all clones for that gene are incorrect; in some cases where lines had failed QC, alternative clones were microinjected and subsequently passed. For example, the gene Trim66: mice derived from ESC clone EPD0027_3_D06 failed targeting QC (LoA qPCR failed, homozygotes by qPCR not confirmed by srPCR), whereas mice derived from clone EPD0155_5_A11 using an alternative design passed (LoA qPCR passed, homozygotes by qPCR confirmed by srPCR). Another example is the gene Twfl; mice derived from ESC clone EPD0127_5_C07 failed targeting (homozygotes by qPCR not confirmed by srPCR) and neo qPCR QC, but the line derived from EPD0127_5_E05 passed (5' and $3^{\prime}$ LRPCR amplification, homozygotes by qPCR confirmed by srPCR). These experiments help validate the resource as a whole and show that even if one clone may be incorrect, others in the collection for that gene may be correctly targeted.

\section{Discussion}

With all high-throughput projects there is an expected degree of trade-off between the accuracy of the resource and the rate of generation (Gerhard et al. 2004; Ryder et al. 2004). The main method used for the EUCOMM/KOMP resource in screening the ES cell clones during production was by long-range PCR and sequencing, using one primer in the cassette and one beyond the limit of the homology arms of the construct design (most frequently at the $3^{\prime}$ end). Although this method allows rapid detection of correct targeting, it cannot detect a mix of targeted and nontargeted clones, which would require a quantitative PCR approach or Southern blot analysis.

We found that the use of additional long-range PCR assays across the $5^{\prime}$ homology arm performed on ESC colonies did not provide any improvement in the transmission of correctly targeted events, which suggests that mixed ESC clones may be the cause of most of the targeting issues observed. To estimate the frequency of potentially mixed clones, we selected the subset of clones that passed additional LRPCR QC (by either the $5^{\prime}$ or the $3^{\prime}$ end) prior to microinjection and calculated how many then failed QC at the mouse stage (Supplementary Information S5). This method, of course, would not detect mixed clones which then contributed the correct cells to the mouse embryo, so this calculation may be an underrepresentation of the true value.

The reason for mixed-cell populations is most likely the practical limitations of the very-high-throughput nature of the ESC generation of the EUCOMM/KOMP-CSD project, where colonies are manually picked from culture plates; e.g., the JM8A1.N3 cells were much harder to culture and process in the laboratory, which may account for the higher percentage of mixed clones compared to the other lines. However, the contribution of this particular cell line to the total number of targeted alleles in the EUCOMM/KOMPCSD collection is less than $15 \%$, compared to $60 \%$ from the JM8A3.N1. More quantitative, yet practical, premicroinjection QC methods such as loss-of-allele assays (Valenzuela et al. 2003) are required to reduce the transmission of incorrect alleles. QC failure does not represent a problem for the resource since in a great majority of cases there are alternative clones that can be injected for each allele. If alternative clones are not available, however, mixed clones may be rescued by subcloning. When the presence of the $3^{\prime}$ loxP site in "conditional ready" mutants in the collection was analysed, $97 \%$ of strains' genes tested displayed the expected results. The small number of conflicts with the loxP results could be due to a mixed colony of conditional and nonconditional targeted clones or a low rate of false-positive PCRs during the screening. 
Table 3 Proposal for a serial code for rapid and comprehensive display of mouse QC

\begin{tabular}{|c|c|c|c|c|c|c|c|}
\hline Index & Targeting & Index & 3' $\operatorname{lox} P$ & Index & Cassette structure: & Index & $\begin{array}{l}\text { Additional } \\
\text { insertions: }\end{array}$ \\
\hline 1 & $\begin{array}{l}\text { No confirmation beyond ESC } \\
\text { screen/QC }\end{array}$ & A & $\begin{array}{l}\text { No verification } \\
\text { beyond ESC } \\
\text { screen/QC }\end{array}$ & A & No verification beyond ESC screen/QC & A & $\begin{array}{l}\text { No } \\
\text { verification } \\
\text { beyond } \\
\text { ESC } \\
\text { screen/QC }\end{array}$ \\
\hline 2 & $\begin{array}{l}\text { Either } 5^{\prime} \text { or } 3^{\prime} \text { LRPCR } \\
\text { amplification of a band }\end{array}$ & B & $\begin{array}{l}\text { Amplification } \\
\text { using qPCR- } \\
\text { based } \\
\text { universal } \\
\text { assay }\end{array}$ & $\mathrm{B}$ & $\begin{array}{l}\text { srPCR based assays at various points } \\
\text { along cassette (e.g., lac } Z \text {, neo, } 5^{\prime} \text { FRT) }\end{array}$ & B & $\begin{array}{l}\text { Vector } \\
\text { backbone } \\
\text { PCR }\end{array}$ \\
\hline 3 & $\begin{array}{l}\text { Both } 5^{\prime} \text { and } 3^{\prime} \text { LRPCR } \\
\text { amplification of a band }\end{array}$ & $\mathrm{C}$ & $\begin{array}{l}\text { Amplification } \\
\text { using srPCR- } \\
\text { based } \\
\text { universal } \\
\text { assay }\end{array}$ & $\mathrm{C}$ & $\begin{array}{l}\text { qPCR based assays at various points } \\
\text { along cassette (e.g., lac } Z \text {, neo, } 5^{\prime} \\
\text { FRT); exclusive or in combination } \\
\text { with step B }\end{array}$ & $\mathrm{C}$ & $\begin{array}{l}\text { neo or lacZ } \\
\text { count qPCR } \\
\text { plus step B }\end{array}$ \\
\hline 4 & $\begin{array}{l}\text { Step } 3 \text { plus end sequence } \\
\text { confirmation }\end{array}$ & $\mathrm{D}$ & $\begin{array}{l}\text { Amplification } \\
\text { using gene- } \\
\text { specific } \\
\text { srPCR-assay }\end{array}$ & $\mathrm{D}$ & $\begin{array}{l}\text { Amplification of PCR tiling array across } \\
\text { whole cassette }\end{array}$ & $\mathrm{D}$ & Southern blot \\
\hline 5 & $\begin{array}{l}\text { Loss of WT allele qPCR and/or } \\
\text { srPCR confirmation of } \\
\text { homozygotes }\end{array}$ & $\mathrm{E}$ & $\begin{array}{l}\text { Sequencing of } \\
\text { PCR product } \\
\text { from } C \text { or D }\end{array}$ & $\mathrm{E}$ & Southern blot & $\mathrm{E}$ & $\begin{array}{l}\text { Genome } \\
\text { sequencing } \\
\text { of mouse }\end{array}$ \\
\hline 6 & Southern blot or steps 3 and 5 & $\mathrm{Z}$ & $\begin{array}{l}\text { No } \operatorname{lox} P \text { in } \\
\text { design or no } \\
\text { loxP detected }\end{array}$ & $\mathrm{F}$ & Full sequencing of cassette & & \\
\hline 7 & $\begin{array}{l}\text { Steps } 3 \text { and } 5 \text { (or step 6), and } \\
\text { gene expression analysis } \\
\text { showing knockout/down of } \\
\text { targeted allele }\end{array}$ & & & & & & \\
\hline 8 & Genome sequencing of mouse & & & & & & \\
\hline
\end{tabular}

Our results highlight the importance of confirming the structure of the targeted mutation in strains derived from the EUCOMM/KOMP-CSD resource. Ideally, this can be achieved with Southern blot analysis of the targeted mutation using external probes. In a high-throughput environment we have replaced this technique with a suite of PCR and qPCR assays that yield the same level of QC. All QC assay results performed on mouse lines are displayed on the IKMC (www.knockoutmouse.org) and EMMA (www.emmanet.org) websites. It is important to note that genotyping mice purely by short-range PCR without reconfirming the targeting is risky; nontargeted lines may appear to be homozygous-lethal, as the WTspecific assay will always amplify a product.

In order to continue to unify the mouse QC for IKMC partners and the newly established IMPC (Brown and Moore 2012), and further simplify the interpretation of results for researchers, we propose here a confidence scoring system for the QC categories based on a fourcharacter code. This is summarized in Table 3; scores are assigned based on the level achieved, ranging from no additional QC to whole-genome sequencing. For example, the line Zfp106 EPD0033_4_C03 would be 7CCC and Nek10 EPD0135_5_C07 would be 5CCC. Under this system, the majority of Sanger MGP lines would be $5 \boldsymbol{C C}$, with over $95 \%$ of the collection having a targeting score of 5 or over. This method can also be extended for ESC QC and incorporate additional categories as required (e.g., karyotyping of cells by either chromosome spreads or qPCR-based assays prior to microinjection).

The EUCOMM/KOMP-CSD mutant ES cell collection is an extremely valuable resource for the scientific community. Our data suggest that, in the absence of any additional pre-microinjection QC, $86 \%$ of the ESC clones that achieve GLT produce strains with correctly targeted events, and that a few simple QC assays at the $\mathrm{G}_{1}$ chimera progeny stage can rapidly screen out the majority of incorrect events (for scientists ordering ESC clones from repositories, requesting three clones should give a $99.7 \%$ chance that at least one is correctly targeted). This will not only save money and effort, it will also help reduce the number of experimental animals used, in compliance with 
the 3Rs (Fenwick et al. 2011; National Centre for the Replacement, Refinement and Reduction of Animals in Research (NC3Rs) Mission and Strategy 2012).

Acknowledgments We thank staff from the Sanger Institute's Research Support Facility, Mouse Genetics Project, and Mouse Informatics Group for their excellent support. Alternative ESC clones for the Btbd11 analysis were kindly supplied by Wendy Bushell and Jackie Bryant. This work was supported by the Wellcome Trust under Grant No. WT098051.

Open Access This article is distributed under the terms of the Creative Commons Attribution License which permits any use, distribution, and reproduction in any medium, provided the original author(s) and the source are credited.

\section{References}

Ayadi A, Birling MC, Bottomley J, Bussell J, Fuchs H, Fray M, Gailus-Durner V, Greenaway S, Houghton R, Karp N et al (2012) Mouse large-scale phenotyping initiatives: overview of the European Mouse Disease Clinic (EUMODIC) and of the Wellcome Trust Sanger Institute Mouse Genetics Project. Mamm Genome 23(9-10):600-610

Bradley A, Anastassiadis K, Ayadi A, Battey JF, Bell C, Birling MC, Bottomley J, Brown SD, Bürger A, Bult CJ et al (2012) The mammalian gene function resource: the International Knockout Mouse Consortium. Mamm Genome 23:580-586

Brown SD, Moore MW (2012) The International Mouse Phenotyping Consortium: past and future perspectives on mouse phenotyping. Mamm Genome 23:632-640

Cho H, Mu J, Kim JK, Thorvaldsen JL, Chu Q, Crenshaw EB, Kaestner KH, Bartolomei MS, Shulman GI, Birnbaum MJ (2001) Insulin resistance and a diabetes mellitus-like syndrome in mice lacking the protein kinase Akt2 (PKB beta). Science 292:1728-1731

Church DM, Goodstadt L, Hillier LW, Zody MC, Goldstein S, She X, Bult CJ, Agarwala R, Cherry JL, DiCuccio M et al (2009) Lineage-specific biology revealed by a finished genome assembly of the mouse. PLoS Biol 7:e1000112

Collins FS, Rossant J, Wurst W (2007) A mouse for all reasons. Cell 128:9-13

Duan C, Yang H, White MF, Rui L (2004) Disruption of the SH2-B gene causes age-dependent insulin resistance and glucose intolerance. Mol Cell Biol 24:7435-7443

Fenwick N, Danielson P, Griffin G (2011) Survey of Canadian animal-based researchers' views on the Three Rs: replacement, reduction and refinement. PLoS One 6:e22478

Flicek P, Amode MR, Barrell D, Beal K, Brent S, Carvalho-Silva D, Clapham P, Coates G, Fairley S, Fitzgerald S et al (2012) Ensembl 2012. Nucleic Acids Res 40:D84-D90

Frese KK, Tuveson D (2007) Maximizing mouse cancer models. Nat Rev Cancer 7:645-658

Games D, Adams D, Alessandrini R, Barbour R, Berthelette P, Blackwell C, Carr T, Clemens J, Donaldson T, Gillespie F (1995) Alzheimer-type neuropathology in transgenic mice overexpressing V717F beta-amyloid precursor protein. Nature 373:523-527

Gao J, Cheon K, Nusinowitz S, Liu Q, Bei D, Atkins K, Azimi A, Daiger SP, Farber DB, Heckenlively JR et al (2002) Progressive photoreceptor degeneration, outer segment dysplasia, and rhodopsin mislocalization in mice with targeted disruption of the retinitis pigmentosa-1 $(R p 1)$ gene. Proc Natl Acad Sci U S A 99:5698-5703

Gerhard DS, Wagner L, Feingold EA, Shenmen CM, Grouse LH, Schuler G, Klein SL, Old S, Rasooly R, Good P et al (2004) The status, quality, and expansion of the NIH full-length cDNA project: the Mammalian Gene Collection (MGC). Genome Res $14: 2121-2127$

Guigo R, Dermitzakis ET, Agarwal P, Ponting CP, Parra G, Reymond A, Abril JF, Keibler E, Lyle R, Ucla C et al (2003) Comparison of mouse and human genomes followed by experimental verification yields an estimated 1,019 additional genes. Proc Natl Acad Sci U S A 100:1140-1145

Keane TM, Goodstadt L, Danecek P, White MA, Wong K, Yalcin B, Heger A, Agam A, Slater G, Goodson M et al (2011) Mouse genomic variation and its effect on phenotypes and gene regulation. Nature 477:289-294

Kim IS, Baek SH (2010) Mouse models for breast cancer metastasis. Biochem Biophys Res Commun 394:443-447

Leibovici M, Safieddine S, Petit C (2008) Mouse models for human hereditary deafness. Curr Top Dev Biol 84:385-429

Leystra AA, Deming DA, Zahm CD, Farhoud M, Paul Olson TJ, Hadac JN, Nettekoven LA, Albrecht DM, Clipson L, Sullivan R et al (2012) Mice expressing activated PI3K develop advanced colon cancer. Cancer Res 72(12):2931-2936

Lloyd KC (2011) A knockout mouse resource for the biomedical research community. Ann N Y Acad Sci 1245:24-26

Mouse ENCODE Consortium, Stamatoyannopoulos JA, Snyder M, Hardison R, Ren B, Gingeras T, Gilbert DM, Groudine M, Bender M, Kaul R et al (2012) An encyclopedia of mouse DNA elements (Mouse ENCODE). Genome Biol 13:418

National Centre for the Replacement, Refinement and Reduction of Animals in Research (NC3Rs) Mission and Strategy (2012). Available at http://www.nc3rs.org.uk/page.asp?id=4

Pettitt SJ, Liang Q, Rairdan XY, Moran JL, Prosser HM, Beier DR, Lloyd KC, Bradley A, Skarnes WC (2009) Agouti C57BL/6N embryonic stem cells for mouse genetic resources. Nat Methods 6:493-495

Prosser HM, Koike-Yusa H, Cooper JD, Law FC, Bradley A (2011) A resource of vectors and ES cells for targeted deletion of microRNAs in mice. Nat Biotechnol 29:840-845

Pruitt KD, Harrow J, Harte RA, Wallin C, Diekhans M, Maglott DR, Searle S, Farrell CM, Loveland JE, Ruef BJ et al (2009) The consensus coding sequence (CCDS) project: identifying a common protein-coding gene set for the human and mouse genomes. Genome Res 19:1316-1323

Ravikumar B, Vacher C, Berger Z, Davies JE, Luo S, Oroz LG, Scaravilli F, Easton DF, Duden R, O'Kane CJ et al (2004) Inhibition of mTOR induces autophagy and reduces toxicity of polyglutamine expansions in fly and mouse models of Huntington disease. Nat Genet 36:585-595

Ringwald M, Iyer V, Mason JC, Stone KR, Tadepally HD, Kadin JA, Bult CJ, Eppig JT, Oakley DJ, Briois S et al (2011) The IKMC web portal: a central point of entry to data and resources from the International Knockout Mouse Consortium. Nucleic Acids Res 39:D849-D855

Ryder E, Blows F, Ashburner M, Bautista-Llacer R, Coulson D, Drummond J, Webster J, Gubb D, Gunton N, Johnson G et al (2004) The DrosDel collection: a set of P-element insertions for generating custom chromosomal aberrations in Drosophila melanogaster. Genetics 167:797-813

Schilling G (1999) Intranuclear inclusions and neuritic aggregates in transgenic mice expressing a mutant $\mathrm{N}$-terminal fragment of huntingtin [published erratum appears in Hum Mol Genet 1999 May;8(5):943]. Hum Mol Genet 8:397-407

Skarnes WC, Rosen B, West AP, Koutsourakis M, Bushell W, Iyer V, Mujica AO, Thomas M, Harrow J, Cox T et al (2011) A 
conditional knockout resource for the genome-wide study of mouse gene function. Nature 474:337-342

Spiden SL, Bortolozzi M, Di Leva F, De Angelis MH, Fuchs H, Lim D, Ortolano S, Ingham NJ, Brini M, Carafoli E et al (2008) The novel mouse mutation Oblivion inactivates the PMCA2 pump and causes progressive hearing loss. PLoS Genet 4:e1000238

Valenzuela DM, Murphy AJ, Frendewey D, Gale NW, Economides AN, Auerbach W, Poueymirou WT, Adams NC, Rojas J, Yasenchak $J$ et al (2003) High-throughput engineering of the mouse genome coupled with high-resolution expression analysis. Nat Biotechnol 21:652-659

Van de Pavert SA, Meuleman J, Malysheva A, Aartsen WM, Versteeg I, Tonagel F, Kamphuis W, McCabe CJ, Seeliger MW, Wijnholds J (2007) A single amino acid substitution (Cys249Trp) in Crb1 causes retinal degeneration and deregulates expression of pituitary tumor transforming gene Pttg1. J Neurosci 27:564-573
White JK, Gerdin A-K, Karp NA, Ryder E, Buljan M, Bussell JN, Salisbury J, Clare S, Ingham NJ, Podrini C et al (2013) Genomewide generation and systematic phenotyping of knockout mice reveals new roles for many genes. Cell 154:452-464

Wilkinson P, Sengerova J, Matteoni R, Chen CK, Soulat G, UretaVidal A, Fessele S, Hagn M, Massimi M, Pickford K et al (2010) EMMA-mouse mutant resources for the international scientific community. Nucleic Acids Res 38:D570-D576

Wirths O, Bayer TA (2010) Neuron loss in transgenic mouse models of Alzheimer's disease. Int J Alzheimers Dis. doi:10.4061/2010/ 723782

Wong K, Bumpstead S, Van Der Weyden L, Reinholdt LG, Wilming LG, Adams DJ, Keane TM (2012) Sequencing and characterization of the FVB/NJ mouse genome. Genome Biol 13:R72

Zheng-Bradley X, Rung J, Parkinson H, Brazma A (2010) Large scale comparison of global gene expression patterns in human and mouse. Genome Biol 11:R124 